\title{
Consideration of sweetness, sweetness thresholds and repeat consumption on the liking of oral nutritional supplements by older cohorts
}

\author{
L. Methven ${ }^{1}$, O. B. Kennedy ${ }^{1}$, L. Ladbrooke-Davies ${ }^{1}$, L. Kinneavy ${ }^{1}$ and M. A. Gosney ${ }^{2}$ \\ ${ }^{1}$ Department of Food Biosciences, University of Reading, Reading RG6 6AP, UK and ${ }^{2}$ Clinical Health Sciences, University \\ of Reading, Reading RG1 $5 A Q, U K$
}

Wastage of oral nutritional supplements (ONS) can be up to $60 \%$; particularly in patients reporting dislike of taste (73\%) and sweetness $(56 \%)^{(1)}$. One study reported dislike of ONS sweetness and age-related differences in preferred sweetness level in line with increased sweet thresholds ${ }^{(2)}$. In a study of ONS variants, preference of older consumers was split between less or more sweet variants ${ }^{(3)}$. Target consumption volume of ONS is typically $200 \mathrm{ml}$ per serving. This study aimed to establish the hedonic liking of ONS products at two sweetness levels, and at two time points (initial sipping and after repeat consumption); determine whether liking correlated with sweet thresholds and study differences between two older cohorts. Vanilla ONS was tested as a standard product and as a reduced sweetness variant. The two cohorts, one free-living $(n=32$; mean age 75$)$ and one hospitalised patient group $(n=28$; mean age 84$)$ scored initial liking of ONS at $5 \mathrm{ml}$ consumption and final liking following repeat consumption of approximately $60 \mathrm{ml}$ over a $10 \mathrm{~min}$ period, on a 9-point hedonic scale. Sweetness threshold was determined using an alternative forced choice method (sucrose concentration 0.68 to $10.88 \mathrm{~g} / \mathrm{l})$.

Mean liking scores of the free-living cohort for the standard ONS decreased significantly $(P<0.0001)$ following repeat consumption. Their liking of the reduced sweetness variant was significantly lower initially $(P=0.03)$, and the liking of this product did not alter following $60 \mathrm{ml}$ consumption. Within the hospital cohort, repeat consumption caused a significant decrease in liking of the reduced sweetness product $(P=0.02)$, but not of the standard ONS. Sweetness thresholds differed significantly $(P<0.001)$ between the cohorts, with older patients having a higher mean threshold. Data from the two cohorts were pooled and threshold was compared to both age (below or above 80) and cohort group. Age class did not have a significant effect on threshold, whereas the effect of cohort group was significant $(P<0.05)$. Sweet thresholds did not correlate to liking of the sweet or less sweet ONS variants.

\begin{tabular}{|c|c|c|c|c|c|}
\hline Cohort & Sucrose threshold $(\mathrm{g} / \mathrm{l})$ & Initial liking standard ONS & Final liking standard ONS & Initial liking less sweet ONS & Final liking less sweet ONS \\
\hline Free-living older people & 3.0 & $6.3^{\mathrm{a}} \pm 1.7$ & $5.0^{\mathrm{b}} \pm 1.9$ & $5.2^{\mathrm{b}} \pm 1.9$ & $5.5^{\mathrm{b}} \pm 1.9$ \\
\hline Older hospital patients & 5.5 & $6.8^{\mathrm{a}} \pm 1.8$ & $6.7^{\mathrm{a}} \pm 1.8$ & $6.1^{\mathrm{a}} \pm 1.9$ & $5.2^{\mathrm{b}} \pm 2.3$ \\
\hline
\end{tabular}

${ }^{\mathrm{ab}}$ Liking data are mean results from 9 point scale $\pm \mathrm{SD}$; values within the same row with different superscripts are significantly different as determined by Nemenyi's procedure $(P<0.05)$.

In conclusion, reducing sweetness of ONS did not increase liking in either older cohort. Differences in sweet thresholds were found between the older cohorts, which may have resulted from medication or disease. Increased consumption volume led to decreased liking of ONS. The decrease in liking may be a result of sensory attributes such as mouth drying, mouth coating and metallic, which have been found by trained sensory panel to increase on repeat consumption ${ }^{(4)}$. To improve the compliance of ONS, the negative sensory attributes that increase over consumption time must be reduced.

1. Gosney M (2003) J Adv Nurs 43, 275-280.

2. Law C, Gosney MA \& Kennedy OB (2006) Proc Nutr Soc 65, 56A.

3. Methven L, Kennedy OB, Mottram DS, et al. (2009) Proc Nutr Soc 68, E55.

4. Methven L, Kennedy OB, Mottram DS, et al. (2010) Proc Nutr Soc 69, E99. 